\title{
Final de la Vida Humana y COVID 19: Experiencia desgarradora
}

\section{End of Human Life and COVID 19: Heartbreaking experience}

Rosa Díaz-Manchay ${ }^{1, a, e}$; Josely Pérez-Loaiza ${ }^{1, b, f} ;$ Juver Carrasco-Fernández ${ }^{2, c, g}$; César Ñique Carbajal ${ }^{3, \mathrm{~d}, \mathrm{~h}}$

\section{Señor editor,}

Ser partícipes del final de la vida humana es una actividad connatural de la labor de los profesionales de las ciencias de la salud, sin embargo en situaciones de crisis como el caso de la pandemia del coronavirus que nos muestra un sistema de salud devastado y colapsado, invita a reflexionar sobre la directiva Sanitaria para el manejo de cadáveres por COVID-19 establecida según Resolución Ministerial 171-2020-MINSA, donde se menciona que los familiares directos que podrán asistir durante el procedimiento de servicios funerarios de cadáveres con covid-19, o de caso sospechoso de covid19, no excederá de dos en la cremación o de cinco para la inhumación ${ }^{(1)}$, siendo por lo menos una preocupación y angustia para los deudos no poder velar y despedirse de sus seres queridos como se acostumbra.

En este sentido cobra importancia la reflexión moral de cada profesional de la salud, sobre el sentido de la muerte de los pacientes COVID-19, análisis que puede realizarse a la luz de los principios éticos declarados en el código de ética y deontológico del Colegio Médico del Perú como el de Autonomía, Beneficencia, No Maleficencia y Justicia ${ }^{(2)}$, los cuales se ven afectados, incluso desde una etapa previa como es el tratamiento de esta enfermedad donde por ejemplo un paciente crítico por COVID que requiere hospitalización inmediata y en el peor de los casos internarse en una $\mathrm{UCI}$, no puede ejercer plenamente su derecho a la autonomía y son sus familiares quienes buscan preservar su vida en la medida de lo posible. Asimismo los principios de beneficencia y no maleficencia, han comandado el quehacer médico buscando salvaguardar la vida a toda costa, no obstante se ha observado que en

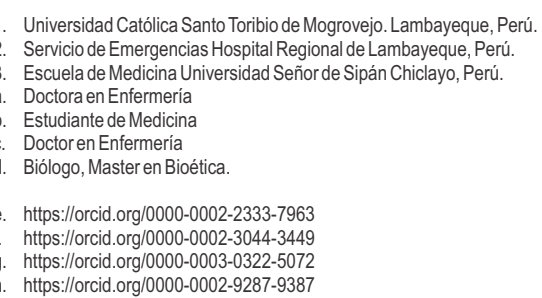

muchos países donde su sistema de salud colapsó llegando a la fase 3 de la pandemia, donde los médicos se encontraban ante la disyuntiva de decidir a quién salvarle la vida: si al anciano, a la madre embarazada o al policía, una difícil situación moral que no permite cumplir con el código y principios de ética que todo profesional de la salud desearía soslayar. De igual modo con respecto al principio de Justicia, según Mendoza ${ }^{(3)}$ debería proporcionar los beneficios y ventajas que les corresponden por igual, el mismo que se ha visto alterado desde mucho antes de la pandemia, ya que el sistema de salud del Perú es segmentado, lo cual genera una jerarquización en las atenciones y en los beneficios diferenciados a recibir.

Todos estos elementos considerados en esta comunicación no tendrían sentido, sin la lectura de una conmovedora descripción de los profesionales de la salud que son los que se encuentran en la primera línea de batalla ante esta Pandemia que ataca a nuestro país, declaración que pasamos a sintetizar:

"Cada turno en un hospital sede COVID 19, es una "pesadilla" está lleno de incertidumbre y cuestionamientos éticos, pues tenemos la desgarradora misión de valorar quién puede sobrevivir para decidir a quién colocarle el oxígeno, quien pasa a ventilación mecánica, es como ser "cómplice" de quién vive y quién muere. Asimismo, es desgarrador ver la expresión de desesperación por falta de oxígeno, y sentir impotencia pues hay carencia de insumos sobre todo el acceso al oxígeno y la ventilación mecánica, y solo nos queda tranquilizar a los pacientes, o si fallece cerrarle los ojos y decirle "que Dios te tenga en su Gloria". Es como ser protagonista de una película de ficción y terror que trata de deshumanización, masacre o muerte, pues a veces el paciente falleció sin darnos cuenta, o nos percatamos del deceso cuando buscamos un punto de oxígeno para otro paciente, o cuando vamos a cerrarle la llave de venoclisis, y murieron solos sin poder recibir apoyo espiritual. $Y$ en ese instante se "aprovecha" para "meterlo en una bolsa" como si fuera una "cosa", sin hacerle el ritual post mortem, luego lo colocan en una caja y nuevamente lo envuelven para llevarlo a un "horno" e incinerarlo. No habrá sepelio siguiendo sus costumbres o rituales familiares, no 
habrá consuelo para el familiar, no existirá despedida, ni ningún evento que pueda permitir dar el apoyo a ese ser que ha perdido a un ser amado. De esta manera, el final de la vida por COVID 19, se ha convertido en un evento desgarrador y angustiante para el paciente, la familia y el personal de salud".

Lo antes mencionado, no solo se vive en el Perú, sino en diferentes países como España, donde la soledad en la muerte se ha impuesto como un "imperativo" para prevenir la transmisión de este virus por "la alta contagiosidad y letalidad", pero está siendo cuestionada; pues miles de pacientes han fallecido sin sentir el afecto y la cercanía de sus seres queridos, y más aun sin contar con el apoyo espiritual o religioso conforme a sus convicciones y creencias; situación que puede conllevar a duelos patológicos en el entorno familiar, volviéndolos aún más vulnerables ${ }^{(4,5)}$. No obstante, es importante que los profesionales de la salud en estas épocas se centren en las prácticas de comunicación, empatía y compasión ${ }^{(6)}$, y no sólo luchen contra la enfermedad, sino en ayudar al bien morir ${ }^{(7)}$. En este contexto, es necesario procurar el oportuno acompañamiento de un ser querido en el momento de la muerte, así como el apoyo espiritual como parte de la trascendencia de la persona humana, lo cual hace fructífera la humanización ${ }^{(4,5)}$.

Conflictos de interés: Los autores niegan conflictos de interés.

Financiamiento: Autofinanciado.

\section{REFERENCIAS BIBLIOGRÁFICAS}

1. Ministerio de Salud. Directiva Sanitaria para el manejo de cadáveres por COVID-19. Resolución Ministerial $\mathrm{N}^{\circ}$ 171-2020-MINSA [Internet]. Lima: Ministerio de Salud; 4 de abril de 2020 [consultado 8 de mayo 2020]. Disponible en: https://www.gob.pe/institucion/minsa/normaslegales/470738-171-2020-minsa.

2. Colegio Médico del Perú. Código de Ética y Deontología [Internet]. 2018 [consultado 8 de

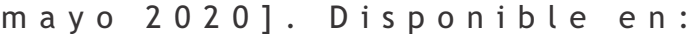
ht tps: / / www.cmp.org.pe / w p content/uploads/2020/01/CODIGO-DE-ETICA-YDEONTOLOG\%C3\%8DA.pdf.
3. Mendoza A. Ética y medicina: la experiencia del Colegio Médico del Perú. Revista Peruana de Medicina Experimental y Salud Pública [Internet]. 2014 [consultado 8 de mayo 2020]; 28(4). D i s p o n i b l e e n : https://doi.org/10.17843/rpmesp.2011.284.433

4. Valle S. Comité de Bioética de España pide que, al menos, un familiar acompañe en la muerte por Covid-19. El mundo ciencia y salud. Madrid, 17 abril 2020. [consultado 8 de mayo 2020]. Disponible en: https: // www.elmundo.es/ciencia-

5. Declaración del comité de bioética de España sobre el derecho y deber de facilitar el acompañamiento y la asistencia espiritual a los pacientes con covid-19 al final de sus vidas y en situaciones de especial vulnerabilidad. El Comité de Bioética de España. En Madrid, a 15 de abril de 2020. [consultado 8 de mayo 2020]. Disponible en: http://assets.comitedebioetica.es/files/docume ntacion/CBE_Declaracion_sobre_acompanamient o_COVID19.pdf

6. Federico Nicoli and Alessandra Gasparetto, "Italy in a Time of Emergency and Scarce Resources: The Need for Embedding Ethical Reflection in Social and Clinical Settings," The Journal of Clinical Ethics 31, no. 1 (Spring 2020): 92-4. [consultado 8 de mayo 2020]. Disponible en: https://www.ncbi.nlm.nih.gov/pubmed/322137 $\underline{00}$

7. Pons Èlia. Entrevista a Marc Antoni Broggi Esta crisis pondrá en valor la necesidad de acompañar el final de la vida. Catalunya Plural. 28/04/2020. [consultado 8 de mayo 2020]. Disponible en: https: / /catalunyaplural.cat/es/esta-crisispondra-en-valor-la-necesidad-de-acompanar-elfinal-de-la-vida/

\section{Correspondencia}

César Ñique Carbajal

Dirección: Av. Miguel Grau 1552 La Victoria Chiclayo Perú.

Teléfono: 743151561

Correo: cesarman2@crece.uss.edu.pe

\section{Revisión de pares}

Recibido: 16/03/2020

Aceptado: 30/03/2020 